cannot be too often repeated, as, in attention to these details above all others, lies the secret of success. After the operation the diseased mucous membrane of the trachea pours fourth a copious exudation of thick, tenacious mucus or pseudomembrane. The inspired air quickly dries it and forms hard sticky masses that obstruct the newly made respiratory tract. These secretions must be kept fluid and the way clear for their expulsion. This is the chief indication in the aftertreatment of tracheotomy. To accomplish it the essentials are :

To keep the apartment at a temperature of about $80^{\circ} \mathrm{F}$, and the atmosphere loaded with moisture.

To administer remedies that are known to stimulate the tracheal and the bronchial mucous glands.

To keep over the tube a thick cravat of several folds of gauze or a piece of wet sponge, to further moisten and warm the in-going air.

To frequently change and clean the inner canula.

To use occasionally, in all cases, the steamatomizer for twenty or thirty minutes at a time, and when the membrane forms fast and dries rapidly, to pour into the opening of the canula from one-half to three-fourths of the time a heavy steam spray of a mildly alkaline or solvent solution with the atomizer placed but a few inches from the canula.

Lastly, when, regardless of persistence in these measures, the trachea becomes obstructed, to remove the canula from the wound, and by instillation with a few drops of water, or with forceps, a feather or other instrument to search for and remove the obstructing mass, as would be necessary with any other foreign body.

Mr. Chairman, in bringing this very imperfect paper to a close, I wish to make a plea for more frequent operative interference in pseudo-membranous laryngitis. Whether it be intubation or tracheotomy that the physician may select is not a matter of importance so long as one is done. Without operative interference these children die, while with it a magnificent percentage recover. Every physician when confronted by a patient in the condition demanding tracheotomy, should have before his mind these eloquent words of Dr. Pilcher: "How long am I justified in deferring the application of a remedy which at once puts an end to grave sources of danger now present to my patient? The most approved methods of treatment have failed to arrest the course of the disease. There is a steady progression in its gravity. A possibility exists, however, that even at the last moment a favorable turn may take place and recovery follow. In all probability, nevertheless, it will steadily advance to a fatal termination. Shall I now give him the benefit of tracheotomy, with its unquestioned advantages, or shall I wait yet longer? Each hour of waiting now will lessen rapidly the hopes which even tracheotomy affords. What is my duty to my patient? What other answer can there be than that justice to my patient, justice to myself, fidelity to the profession 1 represent, all unite in demandiug that Now, early, before the development of conditions which will make any interference but a forlorn hope, tracheotomy should be done."

544 Jefferson Ave.

\section{DOUBLE UTERUS AND VAGINA.}

Read in the Section on Obstetrics at the Thirty-ninth Annual Meeting of the American Medical Association, Cincinnati, Ohio,
May, I8s8.

BY L. H. DUNNING, M.D., OF SOUTH BEND, IND.

Under the general title of double uterus and vagina I wish to consider the congenital malformations of the uterus described and classed by authois as uterus bipartitus, uterus unicornis, uterus bicornis, and uterus bilocularis, when one of these malformations is associated with a double vagina. My observation was directed to this subject something over a year ago, by having brought under my treatment a case of uterus bilocularis, associated with a double vagina. It was a case specifically described by Kussmaul under the name of uterus septus, vagina septa. Brief notes of my case are as follows:

Mrs. A., aged 37 years, married some months and never pregnant. Came to my office with her husband to consult me on account of something abnormal they had found about the genital organs. The following facts were elicited, viz.: Menstruation had begun when the patient was quite young, but had always been irregular and generally scanty. During the last two years they had been at times painful. Since marriage pregnancy had not occurred, but coition had not been painful and there were no symptoms pointing to serious uterine trouble.

Upon ocular inspection and digital examination the external genital organs were found normal and well developed. Upon separating the labia and looking into the ostium vagince nothing abnormal would have been noticed upon casual examination. Upon close examination two vaginæ were found, separated by a moderately thick septum extending from a groove between two cervices to the introitus vagina. The right vagina was considerably larger than the left, and was undoubtedly the one used in coition. The finger entered this one readily, while the left one needed to be searched for. A cervix was found in each vagina and were normal in all respects except the left one was smaller, and both were shorter than normal. The probe entered the right uterine cavity 2 inches, and the left one $\mathrm{I} / 2$ inches. The points of the probe could not be made to meet and their 
handles diverged slightly. No communication between the uterine cavities or vaginal pouches could be made out. By conjoined manipulation the uterus was found to be of normal size, except that the transverse of the body was greater, and there was a slight depression at the fundus, marking the division of the body of the uterus. That portion lying to the left of the depression was onethird smaller than that upon the right side.

About one month later the husband came to my office reporting that his wife had not had her menses, and that they thought her pregnant. Three months later she was seen by the writer and pregnancy found to exist. The labiæ and vaginæ had grown considerably, and were now of that livid hue sometimes indicative of pregnancy. The cervices had enlarged and softened and the right side of the uterus had enlarged, so that it, with its contents, was as large as a normal pregnant uterus at the fourth month. The left side of the uterus had not correspondingly developed, it being apparently flattened out and lying like a molehill upon the left side of the impregnated uterus.

From this time on I saw the patient frequently, and became thoroughly convinced she would be able to effect delivery without operative interference. In due season labor came on in a normal manner. When I was called it had advanced well into the first stage. The right os was dilated to the size of a silver dollar, while the left one was nearly as large. The bag of waters protruded from the right os, and the fotal head was felt just within it. In another hour the right os was largely dilated with a large bag of water protruding from it. The left os was also large and I could determine the position of the fotal head through it as well as through its neighbor. It was found during this examination that there was a communication between the two sides half an inch above the internal os. The finger could be passed into one os through this opening and out the other os. The uterine septum had been torn and it was thought strongly probable that the head would tear the vaginal septum before it in its descent. This actually occurred. The second stage of labor was of four hours' duration and the pains were only moderately severe. At the vaginal outlet a band of the septum remained and was stretched antero-posteriorly over the centre of the fotal head and for a brief time retarded labor. By pushing the head back in the absence of pain this band could be pushed toward the left side, but not far enough to allow the passage of the head. Finally, after three or four pains, the band suddenly gave way, and the head was as suddenly born. The remainder of the child quickly followed, as also did the placenta. There was but little hæmorrhage or shock and the patient was at the end of labor in an excellent general condition. Strict antiseptic precautions were observed and at the end of two weeks the patient had made a complete recovery. When this case came under the writer's observation he began looking up the literature of the subject of double vagina and uterus, and found that contained in one language very meagre, and hardly satisfactory to one desiring to obtain a comprehensive knowledge of the subject. Todd's "Cyclopædia of Anatomy and Physiology" gives a brief but excellent anatomical description of congenital malformations of the uterus, but has little to say regarding double vagina. In the following works much valuable information may be found, viz.: Lusk's "Midwifery," Hart and Barbour's "Manual of Gynæcology," Fritsch's "Diseases of Women," Barnes' "Diseases of Women," and in Turner's articles in the Edinburgh Medical Journal, Feb., I865, and May, I866: The writer of this article has, by the invaluable aid of a physician having access to the Library of the Surgeon-General's office, collated and tabulated the histories of 97 cases of double uterus and vagina. Brief references to some of the facts thereby obtained may be of some interest. Before proceeding to this part of our subject a short anatomical description of the various forms of the malformations will not be inappropriate. Todd ${ }^{1} \mathrm{di}^{-}$ vides congenital malformations of the uterus into four groups.

Ist. Uterus Bipartitus. - In this group the ducts of Muiller are imperfectly developed, or undeveloped, and the result is a more or less complete absence of the uterus. The examples of complete absence of the uterus reported are believed by Todd to be cases in which the rudiments exist, sometimes with a fold of peritoneum lying behind the bladder. 'The concomitants of this condition are usually rudimentary ovaries and Fallopian tubes, a short vaginal cul-de-sac, a complete absence of the vagina, or in rare cases a complete vaginal pouch. In rare instances the ovaries will be found normal, and in still rarer instances there will be a pervious os communicating with the vagina, and the uterus, Fallopian tubes and ovaries sufficiently well developed to permit of conception and delivery. The presence of normal ovaries concomitant to rudimentary condition of the uterus may be understood when it is remembered that the "ovary is formed out of a separate portion of blastema of that from which the Wolffian bodies and excretive duct of the genitive apparatus are developed," so that the failure of growth of one does not necessarily involve a corresponding defect in the other. In this class is the greatest deviation from the normal development of the uterus.

2d. Uterus Unicornis, or the single-horned uterus, is the next in the order of the greatest departure from the normal in development. Here one uterine cornu retains the imperfect condition, while the other undergoes development, so that

I Todd's Cyclopredia of Anatomy and Physiology, vol. v, p. 678 . 
the uterus will consist of a developed and an undeveloped half, or there may be an entire absence of one cornu. Where a rudimentary horn is found this is then solid, or hollow, closely connected to its fellow or only joined to it by a pedicle, which may be either pervious or impervious. The ovary upon the side of the rudimentary horn may be absent, undeveloped, or normal. The Fallopian tube may be pervious or impervious. When the ovary is absent or imperfectly developed it is not unusual to find an absence of the kidney upon the corresponding side. In this group the vagina may be double or single. If it be double one side is likely to be rudimentary or much smaller than its fellow.

3d. Uterus Bicornis, or Toro-horned Uterus.This form of malformation is more frequently met with than either of the former ones. Here the uterine cornua generally develop symmetrically, yet with an imperfect junction of their lateral borders. There is in this class no evidence of plurality or duplicity of the uterus. The condition is due to defective development or failure to fuse of the lower extremities of the ducts of Muiller, and a consequent conjunction of the two halves, as occurs in a normally developed organ. In some instances in this group there is no fusion whatever and there would appear to be two separate organs, and yet examination shows in every instance but a single ovary tube and round ligament for each horn, and thus is demonstrated the fact that the malformation is due to defective development, rather than to a duplicity of organs.

The uterus duplex bicornis and uterus dedilphy's are subdivisions of this group, and they differ from each other chiefly in the degree of the separation of the cornua. In the latter the separation is complete, so that each cornu is capable of movement independently of the other. In this group, as a concomitant, the vagina may be single or double, as also may be the cervix and os.

rudimentary condition of one horn may exist.

4th. Uterus Bilocularis. - The slightest deviation from the normal will be found in this group. Here the uterine cornua are partially fused and may be equally or unequally developed. Usually a groove or fissure will mark the separation of the cornua, while the cavity is more or less completely separated into two parts by a septum. The vagina is also frequently divided into two parts by a septum. When this occurs there may be a cervix in each vaginal tube, or the septum may divide a single os into two parts. The writer's case was of this group, and in it the septum extended from the osteum vagina to the fundus of the uterus. Of the 97 cases the histories of which the writer has collected there were found examples of each one of the groups described. They were as follows :

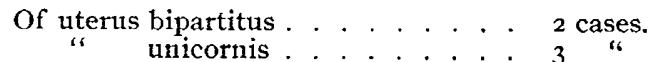

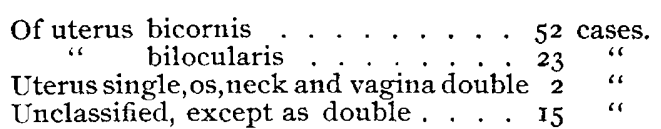

Of these cases the vagina was double, i.e., divided into two parts, in 77 instances ; single in 5 ; absent in $I$; and not stated, but probably double, in I6; and there was atresia of one vagina in 6 cases. Some interesting and instructive facts relative to pregnancy were obtained. Of the 97 women having the malformation, 47 were married, and those who bore children whose marriages were questioned were 3 , thus making in all 50 possible mothers. Of these, 42 women were pregnant 76 times. There were 42 natural deliveries, and 13 difficult labors. The means of relief in the difficult labors were forceps in 7 ; turned in $\mathbf{I}$; septum of the vagina cut in 4 ; and in $I$ there was rupture of the uterus. The number of deaths at, or as a result of labor, was 4 ; I of convulsions; I of rupture of the uterus ; I cause not stated; and I of puerperal fever three weeks after delivery. Fourteen women miscarried 18 times.

It is interesting to know which one of the varieties of malformation we have described is most liable to become pregnant and what is the result in each case. Is the one-horned uterus less liable to become pregnant than the uterus separatus, and if pregnant is it more liable to result in miscarriage, or is labor more liable to be difficult or disastrous? In our list no instance of a pregnant uterus bipartitus is found. Pregnancy occurred in uterus unicornis in 3 women; in uterus bicornis in $2 \mathrm{I}$ women; in $\mathrm{I} 2$ women having uterus bilocularis; in 4 in which the uterus was single, but vagina double; and in 2 of unclassified form. Of the cases of artificial delivery 6 occurred in uterus bicornis ; 2 in uterus bilocularis; and I unclassified form.

These facts are what we would be led to expect when we remember the peculiarities of each class. The one-horned uterus is equally surrounded by muscular tissue, and will nearly or quite right its position in the pelvis before the end of the period of gestation. In uterus bicornis the deficiency in muscular tissue upon the inner aspect of the organ, or inability to rightly employ that tissue, either or both tend to make labor more difficult or protracted. There are two factors operative in removing the axis of the plane of the uterus from the axis of the plane of the vagina, viz.: The commissure (Todd) frequently placed between the separated horns of the uterus, the position and thickness of which determining the angle at which the diverging horns will meet in the grooved uterus, the action of the round ligament which being attached to one horn only of the uterus tends to keep it well outward in the process of development.

But what influence do the different forms of malformation have upon the ability of the preg- 
nant woman to carry the fotus to full term? Our data is not sufficient to enable us to settle this question beyond controversy, yet the facts we find are quite suggestive.

Of the uterus duplex bicornis there were 6 pregnancies and I miscarriage; of the uterus bicornis, 5 pregnancies and I miscarriage; of uterus didelphys, 10 pregnancies and 5 miscarriages; of uterus bilocularis, I 2 pregnancies and 6 miscarriages; of uterus unicornis, 3 pregnancies and no miscarriages. The large percentage of miscarriages in uterus bilocularis is due quite largely to the lodgment of the ovum in the decidua vera in the superior posterior portion of the uterine cavity near enough the septum so that as the placenta develops it spreads over upon the septum and hæmorrhage, or failure of growth frequently occurs, and miscarriage follows. The reason of the frequent abortions or miscarriages in uterus didelphys will, I believe, be found (a) in the unfavorable position the impregnated uterus gradually assumes as the period advances, which position interferes with its circulation, and (b) in the sympathetic excitement induced by the menstruation of its fellow.

What are the effects of the abnormalities under discussion upon menstruation? Menstruation is a function requiring for its normal performance a complex system of organs which must be perfectly formed, in perfect working order, and each bearing its proper relations to all others. Here we have abnormalities affecting a part or the whole of the organs of the menstrual system, and the abnormalities are those of development. The organs affected are chiefly the uterus and vagina, for it is not common to find errors in the formation of the ovaries in cases of double uterus and vagina even in the highest types of the malformation, for reasons already stated. To be more specific, there must be, in order to perfect menstruation, a normal ovary, a pervious tube, normal uterine mucosa, and a pervious os and vaginal tube. These are not always present and when they are not menstrual disturbances will arise.

The most disastrous of these disturbances we have found in our studies are hæmatomatra; the menstrual fluid being retained in the uterus in consequence of an impervious os, and hæmatocolpus resulting from atresia of one vagina. The former of these most frequently occurs in cases of uterus bicornis, but it is sometimes met with in a rudimentary horn which contains normal uterine mucosa and no communcation between the developed and undeveloped horn. We found records of many cases in which menstruation was irregular, scanty, or painful, and some striking anomalies, some few of which may be mentioned. In one instance the patient gave birth to twins at six months from one uterus, menstruated regularly from it three times and then gave birth to a perfectly formed child from the other uterus. In another instance menstruation occurred from both uteri and both became pregnant. Abortion occurred, and it was then ascertained that one uterus had been impregnated three months while the other only one month. It was also learned that both uteri may menstruate at the same time, or that they may alternate in the performance of the function. These facts all tend to emphasize the importance of the place the uterus occupies in the system of organs involved in the performance of the function of menstruation. If with a single uterus and two ovaries menstruation occurs normally every four weeks, and if with a double uterus, each half having a single ovary, the menstrual flow occurs from each every four weeks it would seem quite conclusive evidence that the uterus, and not the ovary, is the most important part of the menstrual system and, it would too, the writer thinks, tend to prove the cycicle nature of this functional manifestation, with the uterus as the center of the system.

What effect does the duplex condition of the vagina have upon the mature woman in respect to menstruation, married life, pregnancy, and delivery? Upon these points our text-books have little to say, but the writer has found in his investigations this is one of the most important parts of his study. Atresia of one or both vaginæ will lead to the formation of a hrmotocolpus. The suffering attending this pathological condition is great, while the dangers to life incident to operative procedures for its cure are also great. The subjects of duplex vagina are usually ignorant of its existence until after marriage, when they find coition painful or impossible. Occasionally a physician will be confronted during the progress of a difficult labor by the presence in the vagina of a firm septum, or he will recognize the existence of a double vagina in which there is a thick, firm, fleshy septum. In the list of cases we have studied ( 97 in all) we have found the septum described as complete, $i$. $e$., extending from the osteum vagina to the cervix uteri, in 72 instances. The following facts appear respecting the septum, viz.: The septum delayed labor in 2 cases, was cut away during labor in 3 cases, torn away in labor in 5 , divided before labor in $\mathrm{I}$, divided for painful coition in 6 , for relief of diseased conditions in 4 , sloughed away after delivery in I, and was divided for atresia of the vagina in 6 cases. In one of the patients having vaginal atresia of one side the foetus passed into the occluded vagina and had to be removed by incision.

It will be seen by this statement that the septum was an important factor in labor in 13 patients, or in more than one-third the women who were confined, as in only 36 of the child-bearing women was there a vaginal septum. It is pertinent to inquire what shall be our mode of procedure respecting this septum? If seen before pregnancy in the married woman it should be, if thick, firm 
and unyielding, incised; excised, or severed by the galvano cautery. As a rule, the writer believes, it will be the best surgery to excise the septum and suture the edges of the mucous membrane, in order to avoid as nearly as possible resulting cicatricial tissue in the vagina. If an incision alone is used it should be crucial, in order that the incised surfaces may not come in contact and adhere. Should the patient be not seen until after pregnancy has occurred the operative procedure is best delayed until the fourth or fifth month.

There is nothing to contraindicate the severing of the septum during labor if it be found materially retarding labor. It is better to cut the septum than to allow it to be torn away as it was in the writer's case. Fortunately his inactivity did not entail upon his patient disaster or serious results, but he would not again hazard the risk of such an occurrence. The best operative means for the relief of hrmotocolpus has not yet been decided upon. Emmet boldly advocates free incision, immediate evacuation of the retained fluid and antiseptic irrigation of the cavity. The weight of authority seems to be against this method and in favor of puncturing the tumor and slowly draining off the retained fluid. Of the 3 cases in our list all were punctured; one died, one recovered, and in one the result is not stated, though it probably recovered. Similar results are shown in the three cases of hæmatomatra in the list. The writer has in his possession the histories of 20 cases of hæmatomatra treated by various methods and cannot forebear anticipating his paper by stating that by far the highest rate of recoveries is found in those instances in which a free incision was made and free drainage and irrigation employed.

Our conclusions are

I. Congenital malformations of the uterus and vagina are of more frequent occurrence than the experience of one man would lead him to suppose.

2. Of the forms of malformation of the uterus associated with double vagina the uterus bicornis is the most frequent, $5 \mathrm{I} .5 \mathrm{per}$ cent. belonging to this class.

3. Except in uterus bipartitus the fecundity of the woman having the malformation is not materially diminished,

4. The ratio of difficult labors is greater than in those having normal uteri. 24. I per cent. were difficult labors; 28.5 per cent. being of uterus bicornis, and 16.66 per cent. being of uterus bilocularis.

5. The forms of malformation in which abortion or miscarriage is most liable are uterus didelphys and uterus bilocularis. In these 50 per cent. of the cases so resulted.

6. Both sides of the uterus may be pregnant at the same time and the fotus in each in the same stage or different stages of development.
7. Disordered menstruation is of frequent occurrence. Atresia of one vagina will be found in about 8 per cent. of the cases. Stenosis of the cervix uteri is sometimes present.

8. Menstruation will take place if there be even a small amount of uterine mucosa and a normal ovary, and if there be not a free exit of the menstrual fluid hæmatomatra will result.

9. Menstruation may occur simultaneously from both uteri or they may alternate in the performance of this function. In the latter case it may appear every two weeks, and from alternate sides.

Io. The two preceding conclusions show the important part the uterus plays in the performance of this function of female life.

SOME OBSERVATIONS, AFTER I,OOO OPERATIONS FOR H王MORRHOIDS.

Read in the Section on Surgery, at the Thirty-ninth Annual Meeting of the American Medical Association, May, 1888 .

BY JOSEPH M. MATHEWS, M.D.,

PROFESSOR OF PRINCIPLES ANV PRACTICE OF SURGERY AND DISEASES OF THE RECTUM, KENTUCKY SCHOOL OF MEDICINE, LOUISVILLE.

Having for a number of years given special attention to diseases of the rectum, I have thought that this paper could be made more or less interesting by recording my individual experience in the operations looking to the relief of hæmorrhoids. I have based my conclusions from operations done upon patients taken indiscriminately from hospital, dispensary, and private practice. Believing that an individual experience is worth much in forming an estimate. I give mine for what it is worth.

Internal Hamorrhoids. - This I believe to be the most common of all rectal affections, though Mr. Allingham believes fistula in ano to be. In making this estimate I rule out the diagnoses made by patients, who usually pronounce any and all affections of the rectum or anus to be piles.

Causes. - With deference to our French confrères, I am satisfied that constipation is the chiefest among the causes of hæmorrhoids. Nor can I subscribe to the belief that through the dissections made by Verneuil we find sufficient evidence in the peculiar distribution of the veins, and the course they take in the coats of the rectum, to disprove the theory that constipation, sedentary occupations, drastic purgatives, prolonged use of enemata, etc., can institute true hæmorrhoids. His idea that the superior hæmorrhoidal veins pass through "veritables boutonniéres musculaires," and that these muscular button-holes have the power of contracting and causing such stasis and congestion in the superior hæmorrhoidal veins as to cause the "primum mobile" in the formation of internal piles, I do not believe. Upon this theory was dilatation of the two sphincter muscles stiggested as a cure for internal hæmor- 